\title{
CIV. Improved method of working a capstan
}

\section{Shuldham R.N.}

To cite this article: M. Shuldham R.N. (1817) CIV. Improved method of working a capstan , Philosophical Magazine Series 1, 49:230, 451-452, DOI: 10.1080/14786441708637947

To link to this article: http://dx.doi.org/10.1080/14786441708637947

$$
\text { 曲 Published online: } 27 \text { Jul } 2009 .
$$

6 Submit your article to this journal $\pi$

LII Article views: 3

Q View related articles $₫$ 
quired). The gas evolving from the retort presses on the surface of the liquid in $\mathrm{A}$, and causes it to ascend through the quill into $\mathrm{C}$, until the orifice of the tube being left open, it necessarily bubbles through the liquid; and what does not combine with it, passes through the fluid in the bulb of the safety-funnel, D ; and raising the liquid into the upper cup, finally escapes. In the event of a vacuum in the retort and lower receiver, it is obvious that the air has free access through the communicating tubes of the safetyfunnel and quilled balloon.

The impreguation is very soon effected, as the pressure is great, and as the several parts are fitted by accurate grinding. Much time is saved, and inconvenience, from the usual mode of luting being avoided.

\section{Improved Method of working a Capstan. By Lieut. M. Shuldham, R. N.*}

SIR, - I BEG leave to present to the Society a very simple contrivance of mine for applying, with much ease and dispatch, an additional power to a capstan when required. The method has been tried on board His Majesty's brig Cordelia, and was found to answer. Many naval officers have also approved it, deeming the contrivance a particularly useful one when applied to a ship's capstan.

\section{1 have the honour to be, sir,}

Your obedient humble servant,

No. 49, Great Titclifeld-strect,

Moryneaux Shurdham. April 9, 1816.

To C. Taylor, M.D. Sec.

Copy of a Report of Lieut. George Eyre Powell, First Lieutenant of His Majesty's Brig Cordelia, relative to Lient. Shuldham's Method of applying more Men to the Capstan. I have had an opportunity of trying your plan on the capstan; it answers in every respect as you stated. Indeed, it is too great a purchase; as, yesterday morning, against a strong gale and tide, I clapped on your swifter, and had the pleasure to carry away a seven-and-n-half-inch messenger : got the messenger removed to a fresh part, and carried it also away; so you may judge there was no foolish wind or tide. I was afterwards obliged to have recourse to a runner and pendant. The mes-

* From the Transactions of the Society for the Encouragement of Arts, Manufactures and Commerce, for the year 1816.-The silver medal wits voted for this communication, and a rodel of the capstan is preserved in the Society's repository. 


\section{Olservations on the peculiar Alternations in the Colour}

senger was quite new when we left this place, and had not been used more than five or six times."

Sheerness, Feb 9, 1816.

(Signed) G. E. Pow El, , First Lieut. Brig Cordelia.

To Lieut. Shuldham, छ'c.

\section{Certificate.}

I hereby certify, that I have seen Lieut. SHULDHAM's contrivance for the application of additional men to a capstan, when it is required to have a great strain, and have no doubt of its efficacy; and as it is not attended with any trouble or expense, I think the invention, when known, will certainly be generally adopted, its simplicity and utility being so obvious.

April 26, 1816. (Signed) A. BRown, Commander, R.N.

Reference to the Engraving of Lieut. Shulnham's improved Method of working a Capstan. Plate V. fig. 2.

In addition to the usual manner of placing men between the capstan bars, the ends of the bars should have notches or gaps made in them, in which an endless rope, $A B$, is received, and passes throngh two pulley blocks, $\mathrm{CD}$; thus forming two straight lines, along which men being placed, can act by pulling the ropes in the most efficacious manner upon the capstan.

CV. Olservations on the peculiar Alternations in the Colour of Aniares, or the bright Star in the Heart of the Scorpion, compared with that of other Stars. By Thomas Forster, Esq.

$S_{1 \mathrm{R}},-I_{\text {HAVR heretofore had occasion to notice the mutations }}$ in the colour of the light of some of the larger fixed stars, and have communicated such ohservations through the medium of your Magazine. I have now to commemorate the great, and, I may say, unusual brilliancy of this phænomenon observed last night in the star Antares, which has afforded an opportunity, during the serenity of a long summer's night, of minutely observiing and defining it, together with the concomitant twinkling. Ahout $9^{b} 35^{\prime}$ I first noticed it. The star twinkled a great deal ; and this motion called twinkling, seems to consist of successive dilatation and brightness, and of apparent contraction and dullness, alternating with each other. The alternating colours are deep red and bright white with a tinge of blue. To be more explicit, I have compared the red colour to the colour of copper filings ignited with gunpowder in the pyrotechnical Jerbs, and the white colour to ignited steel filings. The red colour happens in general just at, or a little before, the maximum of 


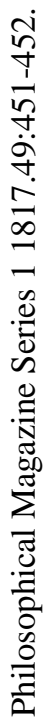

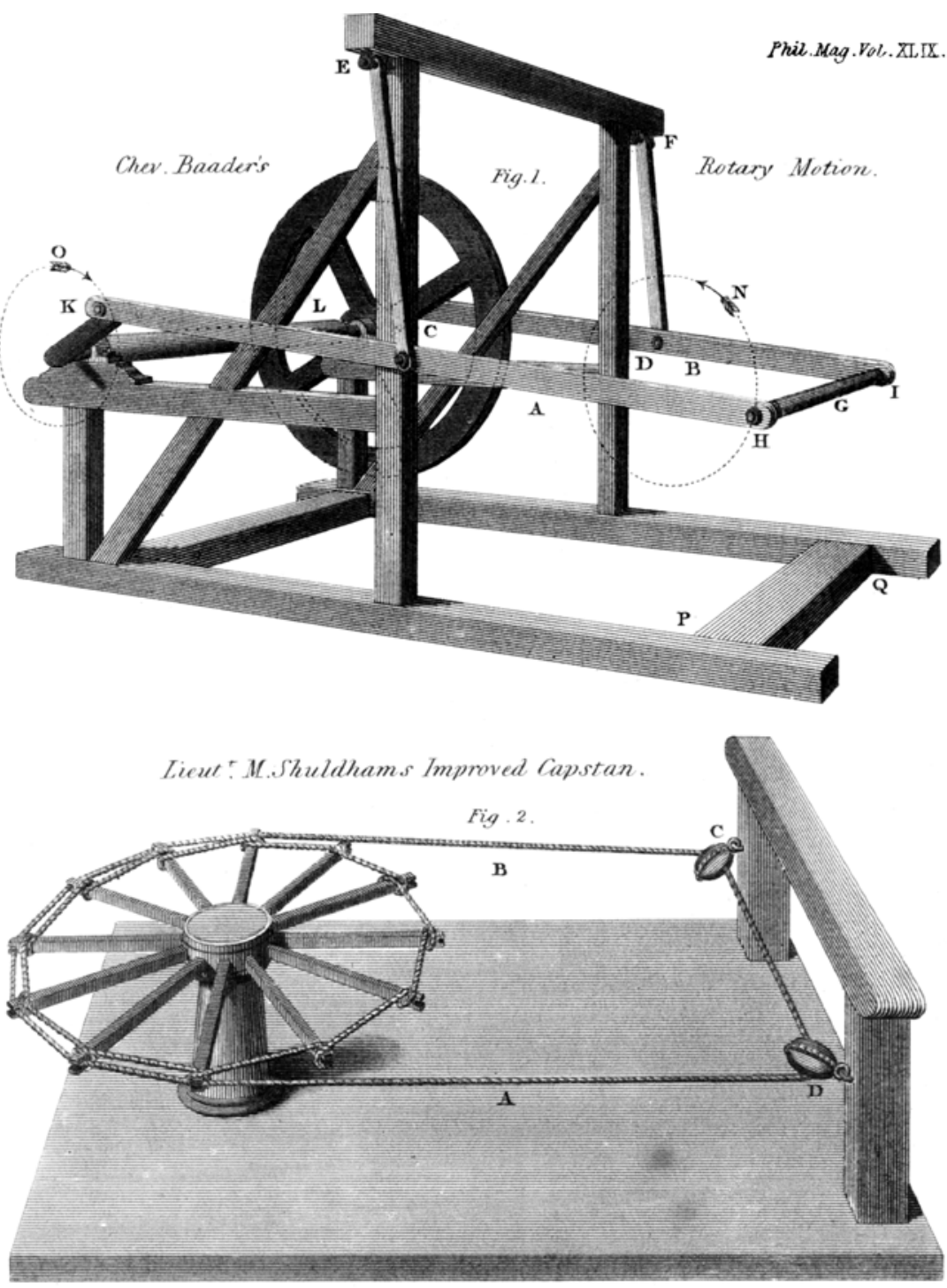

Lieut: M. Shuldhams Improved Capstan

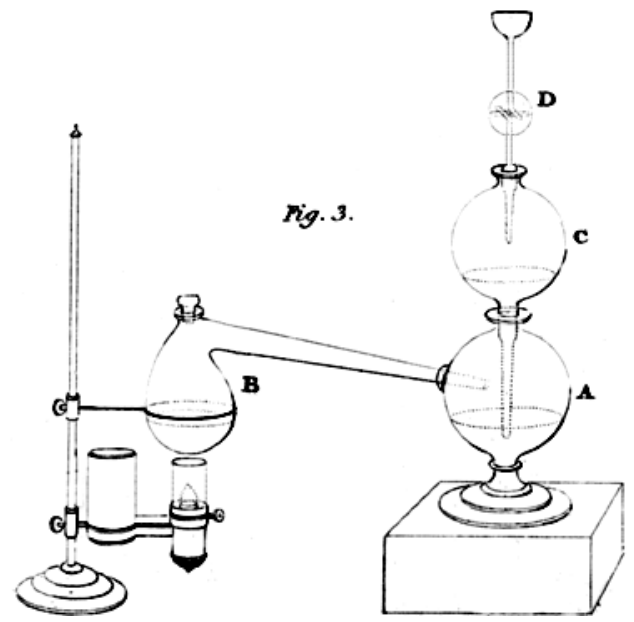

250.

S.Ponter.so. 